\title{
KAJIAN AKSESIBILITAS PADA TAMAN DI PERMUKIMAN (KASUS : TAMAN BUMIREJO, PUDAK PAYUNG, SEMARANG)
}

\author{
Eva Satya Christy ${ }^{1 *}$ ), Rona Fika Jamila ${ }^{2}$, Gentina Pratama Putra ${ }^{2}$, Bangun IR \\ Harsitanto ${ }^{1}$
}

*) Corresponding author email : evasatyachristy@gmail.com

1.) Departemen Arsitektur, Universitas Diponegoro, Semarang - Indonesia

2.) Prodi Arsitektur, Universitas Mercu Buana, Jakarta - Indonesia

\author{
Article info \\ MODUL vol 19 no 2, issues period 2019 \\ Doi $\quad: 10.14710 / \mathrm{mdl} .19 .2 .2019 .104-109$ \\ Received : 20th october 2019 \\ Revised : 4th november 2019 \\ Accepted : 15th november 2019
}

\begin{abstract}
Abstrak
Taman merupakan salah satu ruang publik kota yang memiliki fungsi penting sebagai tempat melakukan aktivitas interaksi, bersosialisasi, maupun rekreasi. Sebagai salah satu fasilitas umum, sebuah taman harus menerapkan standar aksesibilitas sehingga dapat digunakan oleh setiap orang termasuk penyandang disabilitas. Penelitian ini akan membahas kasus pada Taman Bumirejo Semarang untuk melihat sejauh mana penerapan sarana aksesbilitas yang memfasilitasi kebutuhan difabel. Yang menjadi parameter penilaian pada kajian ini adalah Peraturan Menteri Pekerjaan Umum no. 30/PRT/M/2006 tentang Pedoman Teknis Fasilitas dan Aksesibilitas pada Bangunan Umum. Penelitian ini akan menggunakan metode evaluasi antara data standar aksesiblitas dengan kondisi yang terdapat di lapangan. Hasil evaluasi ini diharapkan dapat memberikan wawasan tentang penerapan fasilitas dan aksesibilitas pada Taman Bumirejo serta masukan terkait fasilitas yang seharusnya diterapkan pada taman tersebut.
\end{abstract}

Keywords: aksesibilitas; ruang publik; taman; permukiman;evaluasi

\section{PENDAHULUAN}

Menurut Roger Scruton (1984) ruang publik memiliki makna sebuah lokasi yang didesain minimal, memiliki akses yang besar terhadap lingkungan sekitar, serta sebagai tempat bertemunya manusia dengan mengikuti norma-norma yang berlaku setempat. Sedangkan menurut Rustam Hakim (1987), ruang publik merupakan suatu wadah yang dapat menampung aktivitas masyarakat, baik secara individu maupun

ES Christy, RF Jamila, GPP Putra, BIR Harsritanto secara kelompok, dimana bentuk ruang publik ini sangat tergantung pada pola dan susunan massa bangunan.

Menurut Carr dkk (1992), secara ideal ruang publik harus memiliki tiga hal yaitu responsif, demokratis, dan bermakna. Responsif dalam arti ruang publik adalah ruang yang dapat digunakan untuk berbagai kegiatan dan kepentingan luas yang memiliki fungsi lingkungan hidup. Artinya ruang publik dapat digunakan oleh masyarakat umum dari berbagai latar belakang sosial, ekonomi, dan budaya serta akses bagi berbagai kondisi fisik manusia.

Carr dkk (1992) mengelompokkan macammacam tipologi ruang public sebagai berikut : Tamantaman publik (public parks), lapangan dan plaza (squares and plaza), taman peringatan, pasar (markets), jalan (streets), lapangan bermain (playgrounds), ruang terbuka untuk masyarakat (community open spaces), jalan hijau dan jalan taman (greenways and parkways), atrium/pasar tertutup (atrium/indoor market place), tepi laut (waterfronts).

Sehingga dapat disimpulkan ruang publik adalah sebuah ruang yang dapat diakses bebas oleh seluruh lapisan masyarakat dan berbagai latar belakang termasuk berbagai kondisi manusia yang berfungsi sebagai tempat masyarakat bertemu, berkumpul, dan berinteraksi. Sehingga dalam perwujudannya fasilitas pada ruang publik harus bisa memenuhi kebutuhan seluruh penggunanya.Kota Semarang sebagai Ibukota Provinsi Jawa Tengah memiliki beragam fasilitas dan bangunan umum. Salah satu fasilitas umum di sebuah kota adalah taman kota. Taman kota terutama di kotakota besar berfungsi sebagai tempat masyarakatnya melakukan aktivitas interaksi, bersosialisasi, dan rekreasi.

Aksesibilitas adalah derajat kemudahan dicapai oleh orang, terhadap suatu objek, pelayanan ataupun lingkungan. Kemudahan akses tersebut diimplementasikan pada bangunan gedung, lingkungan dan fasilitas umum lainnya. Aksesibilitas juga difokuskan pada kemudahan bagi penderita cacat untuk 
menggunakan fasilitas seperti pengguna kursi roda harus bisa berjalan dengan mudah di trotoar ataupun naik keatas angkutan umum secara mandiri.

Wojowasito (1991) mengatakan bahwa accessibility adalah hal yang mudah dicapai. Artinya aksesibilitas tidak hanya sekedar kesediaan segala sesuatu, namun juga kesediaan yang mudah dicapai. Bambang sutantono (2004) menyatakan bahwa aksesibilitas adalah "hak atas akses yang merupakan layanan kebutuhan melakukan perjalanan yang mendasar". Kemudian Bambang Susantono (2004) menambahkan bahwa "Aksesibilitas merupakan suatu ukuran potensial atau kemudahan orang untuk mencapai tujuan dalam suatu perjalanan”.

Berdasarkan pengertian diatas dapat diketahui bahwaa aksesibilitas adalah suatu ukuran kenyamanan atau kemudahan mengenai cara lokasi tata guna lahan berinteraksi satu sama lain dan "mudah" atau "sulit" nya lokasi tersebut dicapai yang terkait erat dengan ketersediaan dan kemudahan

Kota Semarang sebagai Ibukota Provinsi Jawa Tengah memiliki beragam fasilitas dan bangunan umum. Salah satu fasilitas umum di sebuah kota adalah taman kota. Taman kota terutama di kota-kota besar adalah hasil transformasi bagian kota berfungsi sebagai tempat masyarakatnya melakukan aktivitas interaksi, bersosialisasi, dan rekreasi (Setioko dan Harsritanto, 2017). Selain sebagai penghijauan kota, taman kota merupakan fasilitas umum yang seharusnya dapat digunakan seluruh lapisan masyarakat tanpa terkecuali (Jamila, 2016). Disinilah sebuah taman hendaknya didesain dengan memperimbangkan segala kemampuan dari penggunanya untuk memaksimalkan fungsi taman itu sendiri (Ghassani et al, 2019).

Aksesibilitas adalah sebuah derajat kemudahan bagi penggunanya untuk mencapai sebuah objek. Aksesibilitas juga difokuskan terutama bagi para difabel atau penderita cacat untuk menggunakan fasilitas dengan bantuan alat contohnya kursi roda tongkat jalan, dan lain-lain (Jamila, 2018). Dengan adanya aksesibilitas pada setiap fasilitas umum para difabel dapat menikmati fasilitas umum secara mandiri. Hal ini sangat penting dilakukan juga untuk memberikan derajat hak yang sama pada difabel dan orang normal.

Untuk itu penting adanya penerapan aksesibilitas pada fasilitas umum terutama pada taman kota. Menurut Al-Manaf (2017) Kota Semarang melakukan pembangunan taman yang tersebar di seluruh daerah dengan total 21 taman. Dan salah satunya adalah Taman Bumirejo yang terletak di Kelurahan Pudak Payung.

Penelitian ini akan membahas tentang kesesuaian penerapan aksesibilitas pada Taman Bumirejo Semarang menurut standar Permen PU No. 30/PRT/M/2006 yang berisi Pedoman Teknis Fasilitas dan Aksesibilitas pada Bangunan Gedung dan Lingkungan. Penelitian ini diharapkan dapat memberikan wawasan tentang penerapan aksesibilitas pada Taman Bumirejo yang kemudian dapat menjadi masukan bagi taman kota yang seharusnya menerapkan standar tersebut.

\section{METODE PENELITIAN}

Kajian aksesibilitas dan fasilitas pada Taman Bumirejo peneliti menggunakan standar sebagai acuan penelitian, yaitu : Peraturan Menteri Pekerjaan Umum Nomor : 30/PRT/M/2006 tentang Pedoman Teknis Fasilitas dan Aksesibilitas pada Bangunan Gedung dan Lingkungan.

Metode pengumpulan data yang berasal dari dokumentasi lapangan : berupa pengukuran objek dan foto-foto dari setiap objek yang diukur.

Evaluasi aksesibilitas pada Taman Bumirejo peneliti melakukan evaluasi keadaan di lapangan dengan standar dengan untuk menilai apakah Taman Bumirejo dapat dikatakan aksesibel bagi penggunanya.

\section{DISKUSI}

\section{Sekilas Taman Bumirejo}

Taman Bumirejo terletak di Pudakpayung, Banyumanik, Kota Semarang, Jawa Tengah 50265. Taman ini terletak di dekat perumahan Mega Permai.Taman ini merupakan ruang publik yang awalnya adalah lapangan sepak bola. Pada akhir 2017 taman ini dibangun dan dilengkapi dengan area publik dan teater terbuka. Banyak kegiatan yang dilakukan di taman ini baik pagi maupun sore hari. Karena selain terdapat lapangan sepak bola yang selalu digunakan untuk berolahraga, terdapat juga lapangan voli, jogging track dan area bermain anak-anak (gambar 1).

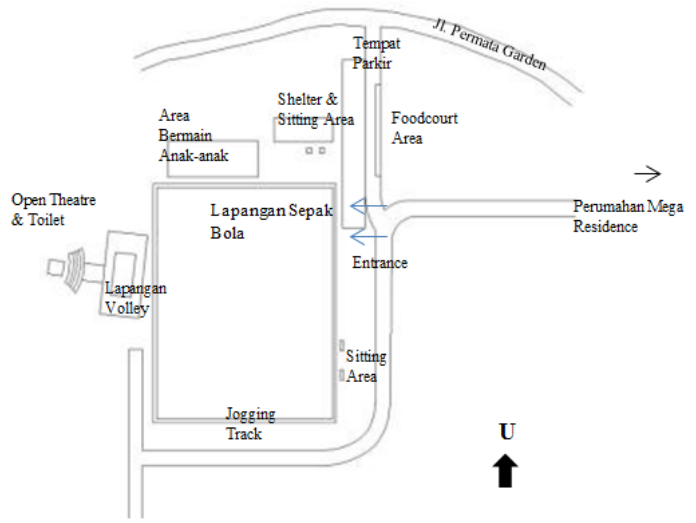

Gambar 1. Kondisi Taman Bumirejo (Christy, 2018)

\section{Jalur Pedestrian}

Terdapat 4 jenis jalur pedestrian di Taman Bumirejo. Jalur pedestrian ini berbeda menurut letaknya, ukuran lebar, maupun material permukaannya (gambar 2). Permukaan pada jalur pedestrian menggunakan 
paving dan batu alam yang halus namun tidak licin. Secara material dan ukuran jalur ini sudah memenuhi persyaratan standar pada Permen PU No. 30 tahun 2006. Namun untuk drainase tidak memenuhi, karena tidak adanya drainase pada jalur pedestrian sepanjang taman. Tidak terdapat tepi pengaman sepanjang pedestrian, padahal ada selokan di sisi jalur yang akan membahayakan penggunanya. Untuk penerangan sudah cukup memenuhi pada pagi sampai sore hari karena diterangi sinar matahari dan pada malam hari juga terdapat lampu di beberapa titik taman (tabel 1).

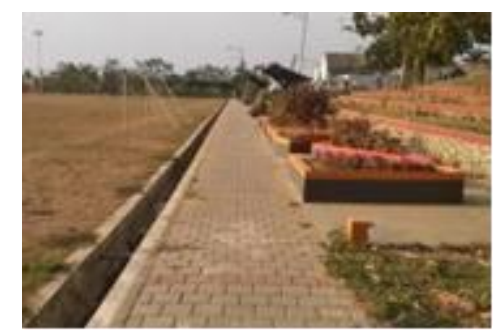

Gambar 2. Kondisi Jalur Pedestrian (Christy, 2018)

Tabel 1. Evaluasi Jalur Pedestrian

\begin{tabular}{|c|c|c|c|}
\hline \multirow[b]{2}{*}{ Sub Variabel } & \multirow[b]{2}{*}{ Deskripsi } & \multicolumn{2}{|c|}{ Taman Bumirejo } \\
\hline & & Sesuai & $\begin{array}{l}\text { Tidak } \\
\text { Sesuai }\end{array}$ \\
\hline Permukaan jalan & Stabil, kuat, tahan cuaca & $\sqrt{ }$ & \\
\hline Tekstur permukaan & Halus dan tidak licin & $\sqrt{ }$ & \\
\hline $\begin{array}{l}\text { Sambungan atau } \\
\text { gundukan }\end{array}$ & $\begin{array}{c}\text { Hindari atau tidak lebih } \\
\text { dari } 1,25 \mathrm{~cm} \\
\text { Maksimal } 2^{\circ}\end{array}$ & $\begin{array}{l}\sqrt{ } \\
\sqrt{ }\end{array}$ & \\
\hline Kemiringan & $\begin{array}{l}\text { Setiap jarak maksimal } \\
900 \mathrm{~cm} \text { harus terdapat } \\
\text { permukaan datar } \\
\text { minimal } 120 \mathrm{~cm}\end{array}$ & $\sqrt{ }$ & \\
\hline Area Istirahat & $\begin{array}{l}\text { Terdapat di bagian tepi } \\
50-150 \text { lux, bergantung }\end{array}$ & $\sqrt{ }$ & \\
\hline Pencahayaan & $\begin{array}{c}\text { pada intensitas } \\
\text { pemakaian, tingkat } \\
\text { bahaya, dan kebutuhan }\end{array}$ & $\sqrt{ }$ & \\
\hline & $\begin{array}{c}\text { Tegak lurus dengan } \\
\text { arah jalur }\end{array}$ & & $\sqrt{ }$ \\
\hline Drainase & Mudah dibersihkan & & $\sqrt{ }$ \\
\hline & $\begin{array}{l}\text { Kedalaman maksimal } \\
\qquad 1,5 \mathrm{~cm}\end{array}$ & & $\sqrt{ }$ \\
\hline Ukuran & $\begin{array}{l}\text { Lebar minimal } 120 \mathrm{~cm} \\
\text { untuk jalur searah dan } \\
160 \mathrm{~cm} \text { untuk dua arah }\end{array}$ & $\sqrt{ }$ & \\
\hline Tepi pengaman & $\begin{array}{c}\text { Tinggi minimum } 10 \mathrm{~cm} \\
\text { dan lebar } 15 \mathrm{~cm} \\
\text { sepanjang jalur } \\
\text { pedestrian }\end{array}$ & & $\sqrt{ }$ \\
\hline & I Nilai & 9 & 3 \\
\hline
\end{tabular}

\section{Jalur Pemandu}

Pada Taman Bumirejo sama sekali tidak terdapat jalur pemandu. Hal ini sangat disayangkan karena taman ini termasuk taman yang baru saja dibangun. Sehingga bagi pengguna taman yang termasuk tuna netra dan low vision akan kesulitan mengakses taman ini secara mandiri.

\section{Area Parkir}

Pada Taman Bumirejo terdapat 2 area parkir yang dipisahkan sirkulasi masuk taman. Area parkir ini merupakan parkir single yang memiliki lebar $6,7 \mathrm{~m}$ (gambar 3). Untuk jarak pencapaian tempat parkir dengan bangunan / fasilitas sudah memenuhi, karena area parkir terletak tepat di sisi utara entrance taman. Namun tidak ada penanda yang membedakan area parkir untuk motor dan mobil. Parkir untuk difabel juga tidak terdapat pada taman ini (tabel 2)..

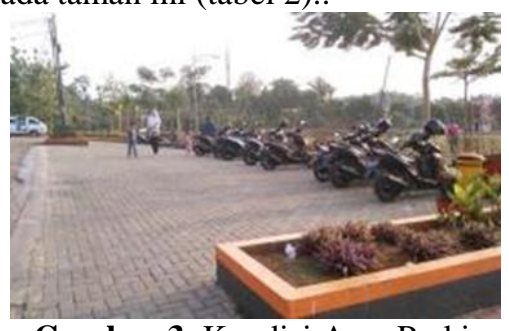

Gambar 3. Kondisi Area Parkir

(Christy, 2018)

Tabel 2. Evaluasi Area Parkir

\begin{tabular}{|c|c|c|c|}
\hline \multirow[b]{2}{*}{ Sub Variabel } & \multirow[b]{2}{*}{ Deskripsi } & \multicolumn{2}{|c|}{ Taman Bumirejo } \\
\hline & & $\begin{array}{l}\text { Sesua } \\
\quad \mathrm{i}\end{array}$ & $\begin{array}{l}\text { Tidak } \\
\text { Sesuai }\end{array}$ \\
\hline Jarak pencapaian & $\begin{array}{c}\text { Tempat parkir menuju } \\
\text { bangunan / fasilitas } \\
\text { maksimum } 60 \mathrm{~m}\end{array}$ & $\sqrt{ }$ & \\
\hline Simbol & $\begin{array}{l}\text { Ditandai dengan } \\
\text { simbol khusus } \\
\text { penyandang cacat }\end{array}$ & & $\sqrt{ }$ \\
\hline Kemiringan & Maksimum $2^{\circ}$ & $\sqrt{ }$ & \\
\hline $\begin{array}{l}\text { Dimensi area } \\
\text { parkir }\end{array}$ & $\begin{array}{l}\text { Parkir single memiliki } \\
\text { lebar } 320-360 \mathrm{~cm}\end{array}$ & $\sqrt{ }$ & \\
\hline $\begin{array}{c}\text { Jumlah tempat } \\
\text { parkir yang } \\
\text { aksesibel }\end{array}$ & $2 \%$ dari total & & $\sqrt{ }$ \\
\hline $\begin{array}{l}\text { Dimensi Passenger } \\
\text { Loading Zone }\end{array}$ & $\begin{array}{l}\text { Lebar minimal } 370 \\
\mathrm{~cm}\end{array}$ & & $\sqrt{ }$ \\
\hline $\begin{array}{l}\text { Simbol Passenger } \\
\text { Loading Zone }\end{array}$ & $\begin{array}{l}\text { Ditandai dengan } \\
\text { simbol khusus } \\
\text { penyandang cacat }\end{array}$ & & $\sqrt{ }$ \\
\hline Ramp Passenger & $\begin{array}{l}\text { Kemiringan } \\
\text { maksimum } 5^{\circ}\end{array}$ & & $\sqrt{ }$ \\
\hline Loading Zone & $\begin{array}{l}\text { Lebar minimal } \\
\mathrm{cm}\end{array}$ & & $\sqrt{ }$ \\
\hline $\begin{array}{l}\text { Handrail Passenger } \\
\text { Loading Zone }\end{array}$ & $\begin{array}{c}\text { Ketinggian } 65-85 \\
\mathrm{~cm}\end{array}$ & & $\sqrt{ }$ \\
\hline Tot & 1 Nilai & 3 & 6 \\
\hline
\end{tabular}

\section{Tangga}

Terdapat 2 buah tangga untuk entrance ke Taman Bumirejo yaitu pada entrance timur dan barat. Untuk tangga pada sisi timur materialnya terdiri dari batu paving sehingga permukaan tidak licin, dan untuk ketinggian serta pijakan anak tangganya sudah memenuhi standar (gambar 4). Namun tidak terdapat handrail pada tepi tangga dan nosing pada masing- 
masing anak tangganya sehingga kurang mendukung masyarakat difabel dalam mengakses tangga secara mandiri.

Sedangkan untuk tangga pada sisi barat materialnya terdiri dari beton yang dilapisi batu alam. Untuk permukaan tangga sudah memnuhi standar, namun ketinggian masing-masing anak tangganya terlalu curam serta tidak terdapat handrail pada tepi tangga. Tangga ini tidak memenuhi standar (tabel 3) .

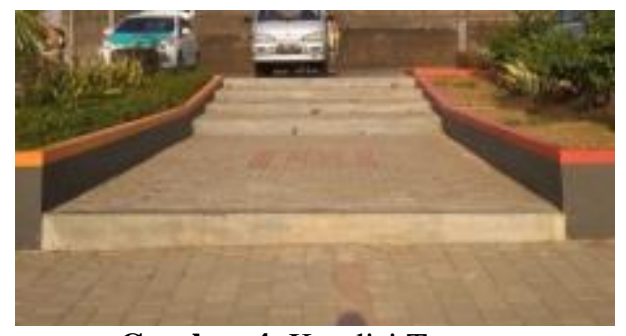

Gambar 4. Kondisi Tangga

(Christy, 2018)

Tabel 3. Evaluasi Tangga

\begin{tabular}{|c|c|c|c|}
\hline \multirow[b]{2}{*}{ Sub Variabel } & \multirow[b]{2}{*}{ Deskripsi } & \multicolumn{2}{|c|}{ Taman Bumirejo } \\
\hline & & Sesuai & $\begin{array}{l}\text { Tidak } \\
\text { Sesuai }\end{array}$ \\
\hline \multirow{2}{*}{$\begin{array}{c}\text { Dimensi anak } \\
\text { tangga }\end{array}$} & Tinggi pijakan 15-19 & $\sqrt{ }$ & \\
\hline & $\begin{array}{c}\text { Lebar pijakan 27-30 } \\
\mathrm{cm}\end{array}$ & $\sqrt{ }$ & \\
\hline $\begin{array}{c}\text { Tekstur } \\
\text { permukaan }\end{array}$ & Tidak berlubang & $\sqrt{ }$ & \\
\hline Kemiringan & Maksimum $60^{\circ}$ & $\sqrt{ }$ & \\
\hline \multirow{3}{*}{ Handrail } & $\begin{array}{c}\text { Minimum salah satu } \\
\text { sisi }\end{array}$ & & $\sqrt{ }$ \\
\hline & Ketinggian 65-80 m & & $\sqrt{ }$ \\
\hline & $\begin{array}{c}\text { Bagian ujungnya harus } \\
\text { bulat atau dibelokkan }\end{array}$ & & $\sqrt{ }$ \\
\hline Nosing & Lebar maksimal $4 \mathrm{~cm}$ & & $\sqrt{ }$ \\
\hline \multicolumn{2}{|c|}{ Total Nilai } & 4 & 4 \\
\hline
\end{tabular}

\section{Ramp}

Pada Taman Bumirejo hanya terdapat 1 ramp yaitu pada entrance taman (gambar 5). Ramp ini memiliki kemiringan $6,4^{\circ}$ sehingga tidak sesuai untuk standar menurut Permen PU No. 30 Tahun 2006 dimana kemiringan maksimal untuk tangga luar bangunan / eksterior adalah $6^{\circ}$. Tekstur permukaan ramp menggunakan paving, sehingga halus tetapi tidak licin, namun tidak memiliki pegangan pada tepinya (tabel 4).

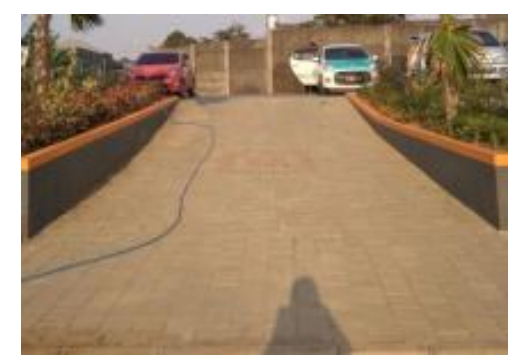

Gambar 5. Kondisi Ramp

(Christy, 2018)

Tabel 4. Evaluasi Ramp

\begin{tabular}{|c|c|c|c|}
\hline \multirow[b]{2}{*}{ Sub Variabel } & \multirow[b]{2}{*}{ Deskripsi } & \multicolumn{2}{|c|}{ Taman Bumirejo } \\
\hline & & Sesuai & $\begin{array}{l}\text { Tidak } \\
\text { Sesuai }\end{array}$ \\
\hline Derajat kemiringan & $\begin{array}{c}\text { Maksimal 6 } \\
\text { (Eksterior) }\end{array}$ & & $\sqrt{ }$ \\
\hline Panjang ramp & $\begin{array}{l}\text { Maksimal } 900 \mathrm{~cm} \\
\left(7^{\circ}\right),<7^{\circ} \text { boleh lebih } \\
\text { dari } 900 \mathrm{~cm}\end{array}$ & $\sqrt{ }$ & \\
\hline Lebar ramp & $\begin{array}{c}\text { Minimum } 95 \mathrm{~cm} \\
\text { tanpa tepi pengaman, } \\
\text { maksimal } 120 \mathrm{~cm} \\
\text { dengan tepi } \\
\text { pengaman }\end{array}$ & & $\sqrt{ }$ \\
\hline $\begin{array}{c}\text { Permukaan datar / } \\
\text { bordes }\end{array}$ & $\begin{array}{l}\text { Bebas dan datar } \\
\text { dengan ukuran } \\
\text { minimal } 160 \mathrm{~cm}\end{array}$ & $\sqrt{ }$ & \\
\hline & Harus bertekstur & $\sqrt{ }$ & \\
\hline Tepi pengaman & Lebar $10 \mathrm{~cm}$ & & $\sqrt{ }$ \\
\hline Pencahayaan & Pencahayaan cukup & $\sqrt{ }$ & \\
\hline Handrail & Ketinggian $65-80 \mathrm{~cm}$ & & $\sqrt{ }$ \\
\hline \multicolumn{2}{|c|}{ Total Nilai } & 4 & 4 \\
\hline
\end{tabular}

\section{Toilet}

Taman Bumirejo memiliki 2 buah toilet yang tidak terdapat simbol pembeda antara toilet pria dan wanita. Simbol "penyandang cacat" juga tidak terdapat di pintu toilet. Toilet ini juga tidak terawat dan salah satu toiletnya tidak dapat digunakan karena pintu masuknya rusak. Pintu dan dimensi ruang toilet juga terlalu sempit sehingga tidak memenuhi standar (tabel 4). Selain itu juga tidak terdapat wastafel pada toilet di taman ini (gambar 6).

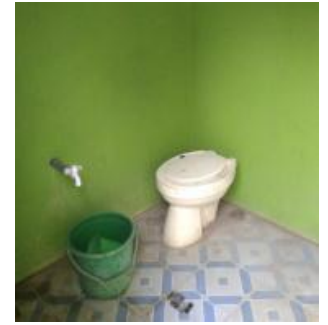

Gambar 6. Kondisi Toilet

(Christy, 2018)

Tabel 4. Evaluasi Toilet

\begin{tabular}{ccc}
\hline \multirow{2}{*}{ Sub Variabel } & Deskripsi & \multicolumn{2}{c}{ Taman Bumirejo } \\
Simbol & $\begin{array}{c}\text { Sistem cetak timbul } \\
\text { "penyandang cacat" pada } \\
\text { pintu toilet bagian luar }\end{array}$ & $\sqrt{ }$ \\
\hline & &
\end{tabular}




\begin{tabular}{cccc}
$\begin{array}{c}\text { Ruang gerak } \\
\text { Ruang }\end{array}$ & $\begin{array}{c}\text { Minimal } 160 \times 160 \mathrm{~cm} \\
\text { Minimal panjang } 110 \mathrm{~cm}\end{array}$ & $\sqrt{ }$ & \\
$\begin{array}{c}\text { tunggu depan } \\
\text { pintu toilet }\end{array}$ & Minimal lebar $160 \mathrm{~cm}$ & $\sqrt{ }$ & \\
Handrail & $\begin{array}{c}\text { Harus dilengkapi dengan } \\
\text { ketinggian } 85 \mathrm{~cm}\end{array}$ & $\sqrt{ }$ \\
Pintu toilet & $\begin{array}{c}\text { Lebar minimal } 90 \mathrm{~cm} \\
\text { Ketinggian tisu } 65 \mathrm{~cm}\end{array}$ & $\sqrt{ }$ \\
$\begin{array}{c}\text { Perletakan } \\
\text { kelengkapan } \\
\text { toilet }\end{array}$ & Ketinggian kloset $45-50$ & $\sqrt{ }$ & $\sqrt{ }$ \\
Lantai & cm & $\sqrt{ }$ & \\
\hline & Total Nilai & 4 & 5 \\
\hline
\end{tabular}

\section{Wastafel}

Pada Taman Bumirejo wastafel hanya terdapat di shelter taman (gambar 7). Untuk ketinggian dan ruang gerak di sekitar wastafel sudah memenuhi standar. Namun tidak terdapat ruang bebas pada bagian bawah wastafel. Serta adanya beton yang menjadi penahan wastafel justru menghalangi ruang gerak dibawah wastafel, sehingga pengguna kursi roda tidak dapat menggunakan wastafel. Namun untuk penggunaan krannya sudah sesuai standar dengan menggunakan kran engkol (tabel 5)

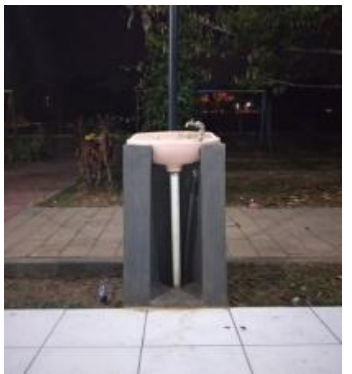

Gambar 7. Kondisi Wastafel

(Christy, 2018)

Tabel 5. Evaluasi Wastafel

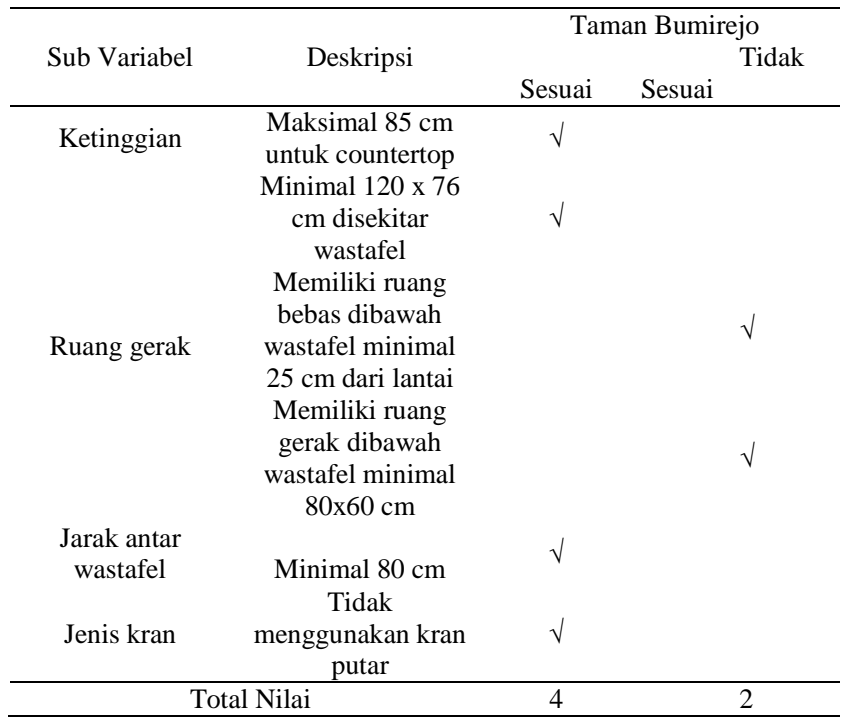

\section{Perlengkapan dan Peralatan Kontrol}

Pada Taman Bumirejo hanya terdapat perlengkapan dan peralatan kontrol berupa saklar lampu dan colokan yang terletak di shelter dan toilet (gambar 8). Ketinggian masing-masing saklar dan colokan adalah $150 \mathrm{~cm}$ dan tidak memenuhi standar pada Permen PU No. 30 Tahun 2006 yang menyatakan tinggi maksimal $120 \mathrm{~cm}$ (tabel 6)

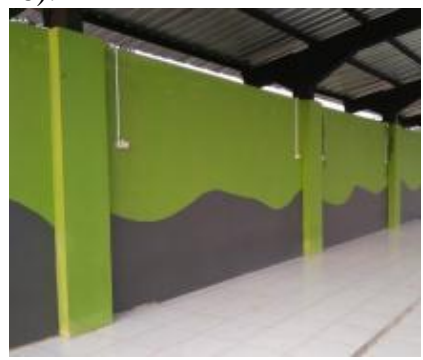

Gambar 8. Kondisi stop kontak dan tombol (Christy, 2018)

Tabel 6. Evaluasi Tombol dan Stop kontak

\begin{tabular}{cccc}
\hline \multirow{2}{*}{ Sub Variabel } & Deskripsi & \multicolumn{2}{c}{ Taman Bumirejo } \\
& Sesuai & Tidak Sesuai \\
\hline $\begin{array}{c}\text { Tombol dan Stop } \\
\text { Kontak }\end{array}$ & $\begin{array}{c}\text { Ketinggian } \\
\text { maksimal 120 } \\
\mathrm{cm}\end{array}$ & & $\sqrt{ }$ \\
\hline \multicolumn{2}{c}{ Total Nilai } & 0 & 1 \\
\hline
\end{tabular}

\section{Rekapitulasi Evaluasi Aksesibilitas di taman Bumirejo}

Untuk fasilitas yang tidak terdapat pada Taman Bumirejo dalam Permen PU No. 30 Tahun 2006 adalah :

a) Jalur Pemandu

b) Pancuran

c) Telepon

d) Rambu dan Marka

Berdasarkan hasil analisa maka dapat disimpulkan persentase pemenuhan persyaratan aksesibilitas menurut Peraturan Menteri Pekerjaan Umum No.30/PRT/M/2006 pada Taman Bumirejo sebagai tabel 7 berikut:

Tabel 7. Rekapitulasi hasil evaluasi

\begin{tabular}{cccc}
\hline Fasilitas & Total Sub Variabel & Sesuai & Tidak Sesuai \\
\hline Jalur Pedestrian & 12 & 9 & 3 \\
Area Parkir & 9 & 3 & 6 \\
Ramp & 8 & 4 & 4 \\
Tangga & 8 & 4 & 4 \\
Toilet & 9 & 4 & 5 \\
Wastafel & 6 & 4 & 2 \\
Perlengkapan dan & 1 & 0 & 1 \\
Peralatan Kontrol & 53 & 28 & 25 \\
\hline Total & $100 \%$ & $53 \%$ & $47 \%$
\end{tabular}

Hasil dari persentase keseluruhan fasilitas di Taman Bumirejo menunjukkan sebesar 53\% memenuhi standar 


\section{KESIMPULAN}

Hasil dari persentase keseluruhan fasilitas di Taman Bumirejo menunjukkan sebesar 53\%. Hal ini dapat disimpulkan fasilitas yang memenuhi persyaratan teknis aksesibilitas masih mendominasi taman tersebut. Sehingga dapat dinyatakan bahwa Taman Bumirejo Aksesibel dan masih memenuhi standar Peraturan Menteri Pekerjaan Umum No.30/PRT/M/2006 tentang Pedoman Teknis Fasilitas dan Aksesibilitas pada Bangunan Gedung dan Lingkungan.

\section{SARAN}

Meskipun nilai dari evaluasi Taman Bumirejo didominasi dengan persyaratan yang sesuai, perlu adanya pembenahan dan penambahan fasilitas pad ataman, diantaranya :

a. Jalur Pedestrian pada Taman Bumirejo seharusnya dilengkapi drainase pada bagian tepi dengan kedalaman maksimal $1,5 \mathrm{~cm}$ dan juga perlu ditambahkan tepi pengaman agar menambah tingkat keamanan jalur tersebut.

b. Perlu penambahan jalur pemandu agar Taman Bumirejo dapat diakses oleh masyarakat difabel terutama untuk pengguna yang termasuk tuna netra dan low vision agar dapat mengakses taman secara mandiri

c. Penambahan area parkir khusus difabel yang terletak dekat dengan taman agar tidak terlalu jauh dalam mengakses Taman Bumirejo.

d. Pada ramp yang terdapat di Taman Bumirejo perlu ditambah tepi pengaman dengan ketinggian $65-80 \mathrm{~cm}$.

e. Semua tangga yang terdapat pada Taman Bumirejo perlu ditambahkan tepi pengaman dan nosing pada tiap anak tangganya.

f. Penambahan toilet difabel pada Taman Bumirejo karena toilet yang sudah ada tidak memenuhi standar untuk dapat digunakan masyarakat difabel terutama yang menggunakan kursi roda.

g. Perlu penggantian desain wastafel agar tersedia area bebas di bawah wastafel.

h. Ketinggian stop kontak dan saklar perlu disesuaikan dengan standar minimal yaitu 120 $\mathrm{cm}$ dari tanah.

\section{PERSEMBAHAN}

Hasil Riset Desain Arsitektur ini disusun atas kerjasama penulis dan tim pembimbing dari internal Universitas Diponegoro dan eksternal kampus Universitas Mercu Buana.

\section{REFERENCES}

Al-Manaf, Rival. (2017) Asyik, Lapangan Bola Dirombak Jadi Taman Bumirejo Dilengkapi
Teater Terbuka. Diambil dari: http://jateng.tribunnews.com/2017/11/26/asyiklapangan-bola-dirombak-jadi-taman-bumirejodilengkapi-teater-terbuka.(3 September 2018)

Carr, S. dkk (1992) Public Space. USA: Cambridge University Press.

Gunama $\mathrm{MG}$ and Latifa NF Automatictecture : Otomatisasi Penuh dalam Arsitektur Masa Depan Arsitektur NALARs Volume 16 Nomor 1 p 4360

Dea Putri Ghassani, Mona Anggiani, Rona Fika Jamila (2019) Studi Perbandingan Kenyamanan Pengguna RPTRA (Studi Kasus: RPTRA Akasia dan RPTRA Pandawa), Vitruvian: Jurnal Arsitektur, Bangunan, dan Lingkungan Vol 8, No 2, p59-66

Hakim, Rustam (1987) Unsur Perancangan dalam Arsitektur Lansekap. Jakarta: Bina Aksara.

Jamila, RF dan Putra, GP (2016) Preferensi Masyarakat Terhadap Kondisi Fisik Taman Honda Tebet, Vitruvian: Jurnal Arsitektur, Bangunan, dan Lingkungan vol 6 no 1 hal 9-14

Jamila, RF (2018) Evaluasi Desain Ruang Publik Ramah Anak Di Rptra Akasia, Vitruvian: Jurnal Arsitektur, Bangunan, dan Lingkungan vol 7 no 3 hal 161-166

Setioko, Bambang dan Harsritanto, Bangun IR (2017) Transformasi Bentuk Dan Pola Ruang Komunal Di Kota Lama Semarang, MODUL vol 17 no 1 hal 11-16

Scruton, Roger (1984) Public Space and The Classical Vernacular. Singapore: The Public Interest.

Susantono, Bambang (2004) Langkah Kecil Yang Kita Lakukan Menuju Transportasi Yang Berkelanjutan. Jakarta: Masyarakat Transportasi Indonesia.

Wojowasito, S. (1991) Kamus Lengkap: InggerisIndonesia. Indonesia-Inggeris. Bandung: Hasta.

Peraturan Menteri Pekerjaan Umum Nomor : 30/PRT/M/2006. 2006. Tentang Pedoman Teknis Fasilitas Dan Aksesibilitas Pada Bangunan Gedung Dan Lingkungan. Jakarta: Kementrian Pekerjaan Umum. 